The Journal of Public Space

ISSN 2206-9658

2020 | Vol. 5 n. 2

https://www.journalpublicspace.org

\title{
Green public spaces in the cities of South and Southeast Asia. Protecting needs towards sustainable well-being
}

\author{
Marlyne Sahakian \\ University of Geneva, Institute of Sociological Research, Switzerland \\ marlyne.sahakian@unige.ch
}

Manisha Anantharaman

Saint Mary's College of California, United States of America

ma20@stmarys-ca.edu

\author{
Antonietta Di Giulio \\ University of Basel, Program Man-Society-Environment (MGU) \\ Research Group Inter/Transdisciplinarity, Switzerland \\ antonietta.digiulio@unibas.ch
}

\section{Czarina Saloma}

Ateneo de Manila University, Philippines

csaloma@ateneo.edu

Dunfu Zhang

Shanghai University, China

dunfuzhang@hotmail.com

Rupali Khanna, Srikanth Narasimalu

Nanyang Technological University, Singapore

rupalikhanna@ntu.edu.sg | nsrikanth@ntu.edu.sg

Abigail Marie Favis, Cherie Audrey Alfiler

Ateneo de Manila University, Philippines

afavis@ateneo.edu | calfiler@ateneo.edu

Sumana Narayanan

Independent researcher, India

sumananarayanan@gmail.com

Xin Gao, Chenxin Li

Shanghai University, China

bemyring@hotmail.com | nixnehclee@shu.edu.cn 


\begin{abstract}
The significance of green public spaces is well documented in relation to social inclusiveness, human health, and biodiversity, yet how green public spaces achieve what Gough (2017) has termed 'sustainable wellbeing' is less understood. This contribution presents preliminary results from a study of green public spaces in four mega-cities of South and Southeast Asia: Chennai (the Republic of India), Metro Manila (the Republic of the Philippines), Singapore (the Republic of Singapore), and Shanghai (the People's Republic of China), cities that have climates ranging from tropical, to subtropical and temperate. The conceptual framework brings together social practice theories with human development theories, methodological implications for the study of park usage, and Protected Needs. This study sets out to understand how parks satisfy human needs by uncovering practices in relation to activities and material arrangements. Central to the research design and sampling strategy is a desire to understand park-related practices in all of their diversity, and accounting for how different activities are carried out by diverse groups of people. The paper presents exemplary results showing that parks provide a space in which a multitude of needs are satisfied, and that parks cannot be substituted by other settings such as commercialized spaces. The paper will conclude by discussing tensions between types of park usage, and in relation to commercial encroachments on public space.
\end{abstract}

Keywords: South and Southeast Asia, protected needs, parks, well-being, sustainability

\title{
To cite this article:
}

Sahakian, M., Anantharaman, M., Di Giulio, A., Saloma, C. Zhang, D., Khanna, R., Narasimalu, S., Favis, A. M., Alfiler, C. A., Narayanan, S., Gao, X., Li, C. (2020). Green public spaces in the cities of South and Southeast Asia: Protecting needs towards sustainable well-being, The Journal of Public Space, 5(2), 89-II0, DOI 10.3289I/jps.v5i2.1286

This article has been double blind peer reviewed and accepted for publication in The Journal of Public Space. This work is licensed under a Creative Commons Attribution - Non Commercial 4.0 International License https://creativecommons.org/licenses/by-nc/4.0/ 


\section{Introduction}

Nowhere but in the cities of the Global South is it more pressing to think about public space in relation to climate. In the hot and humid contexts of South and Southeast Asian cities, anthropogenic processes are leading to climate change and local pollution.

Further, concrete constructions, air-conditioning dependencies, and fuel-based forms of mobility are leading to hotter microclimates in cities as opposed to surrounding areas, or what is known as the urban heat island effect. The notion of 'microclimate as artifact' (Roesler and Kobi, 20l8) draws attention to how the climate as an object is socially constructed and materially-embedded, related to how we plan cities and urban spaces. The prevalence of air-conditioned shopping spaces in the cities of South and Southeast Asia is leading to a homogenization of climate control as the most desirable form of microclimate (Sahakian, 2014; Hitchings and Jun-Lee, 2008), reinforcing class inequalities in relation to who has or is denied access to such spaces, and further structuring leisure activities around commercial spaces. Against this backdrop, studying the role of green public spaces in relation to these climatic and socio-economic contexts becomes all the more pressing.

Green public spaces, in this paper, refer to outdoor spaces which involve some level of biodiversity and are publicly accessible. We draw from Habermas (1989) and Urry (1995), respectively, in seeing the 'public' as a sphere where private people come together, and 'space' as an extension and reflection of society. In this understanding, a green public space can also be privately managed and owned. 'Green' refers to the biophysical dimension of the space, such as biological and microclimate diversity, as opposed to artificially cooled indoor spaces. Public spaces have been studied in the past in relation to biodiversity and social inclusion, building on earlier literature on public spaces in relation to democracy (Lefebvre, 1967), yet rarely are the environmental and social dimensions of sustainability studied together. There is therefore a need to bridge an understanding of ecological factors (Wolch et al., 20I4; Kowarik, 20I I; Gross, 2010; Cornelis and Hermy, 2004) with questions related to access and social equity, including socio-economic, gendered, and ethnic variables (Boone et al., 2009; Seeland et al., 2009; Abercrombie et al., 2008; Barbosa et al., 2007; Krenichyn, 2006). Further, understanding green public spaces as contributing to microclimate diversity is relatively understudied (Tavares in Roesler and Kobi, 2018).

Gough's notion of 'sustainable wellbeing' (2017) is a useful starting point for bringing together an understanding of sustainability that integrates both environmental and social considerations. Sustainable wellbeing involves meeting human needs (thus going beyond human health) while accounting for planetary limits. Gough distinguishes preferences from needs by stating that "meeting needs will always be a lower carbon path than meeting untrammelled consumer preferences financed by ever-growing incomes" (2017: 13). With a view to meeting human needs, Max-Neef (1989) and colleagues introduce the notion of satisfiers: for this paper, we argue that green public spaces act as synergic satisfiers, in that they can serve to meet several needs. Therefore, the main proposition of this paper is that public spaces are crucial to 'sustainable wellbeing' in cities, as they not only harbour biological and microclimate diversity, but also promote individual need satisfaction as well as societal benefits such as: social inclusion, democratic engagement, and opportunities for leisure and livelihood generation, among others.

Our main research question is: in what way do green public spaces contribute to sustainable wellbeing as synergic satisfiers? We focus on four coastal mega-cities in 
South and Southeast Asia: Chennai, Metro Manila, Shanghai, and Singapore. In order to study the role between public spaces and wellbeing, we turn to approaches from philosophy, and the sociology of consumption. In the section below, we present our conceptual framework and methodological approach. The research findings are then discussed by city, followed by a conclusion where we describe the unique threats posed to green public spaces in these cities.

\section{Conceptual framework}

Human wellbeing is a key consideration in sustainability debates (Robeyns and van der Veen, 2007). Yet, as demonstrated in the extensive literature on human wellbeing (Alkire, 2010), quality of life, and happiness, how to conceptualize wellbeing is subject to diverse interpretations (e.g., Cummins, 1996; Dolan et al., 2008; Doyal and Gough, 199I; Ryan and Deci, 2000; Max-Neef et al., 199I; Nussbaum, 1992; Ryff, 1989; or Veenhoven, 2008). In relation to sustainability, distinguishing between legitimate needs and non-legitimate desires on the one hand, and between needs and 'satisfiers' understood here as the products and services, infrastructures or institutions necessary for meeting needs - on the other hand, is a core issue (Di Giulio et al., 20I2). This distinction proceeds from different theories of wellbeing, ranging from Nussbaum's capability approach (1992) to Max-Neef et al.'s needs-based approach (199I) and Costanza et al.'s (2007) integration of a capability and a needs-based approach. The main premise of these theories is that humans have universal needs and that these needs should also reflect cultural and historic contexts. This emphasizes the significance of satisfiers required for meeting needs, which are contextual and specific to varying institutions and cultures (Gough, 2015).

There is little research on the role of green public spaces towards societal wellbeing especially on their potential to provide satisfaction for several needs, what Max-Neef and colleagues (1991) termed 'synergic satisfiers'. Rao and Min (2017) suggest that public spaces can serve "to foster a sense of freedom, for the pursuit of leisure activities, and to congregate for political and social activities" (p. 20), but conclude that further empirical evidence is needed for assessing whose needs are being satisfied.

Needs satisfaction can also lead to conflict: green public spaces may allow for members of the poor and working classes to perform livelihood activities and live private lives, which may create a tension with middle- and upper-class groups who uphold aesthetic ideals and view these spaces as solely viable for leisure. Studying the cross-class dimensions of how people use and benefit from green space, and the conflicts embedded in these uses, is a productive line of inquiry. For this study, the notion of Protected Needs and a corresponding list of needs was utilized (Di Giulio and Defila 2020, see Annex I). This list builds on objective theories of a good life and an intensive review of the literature, and the needs are classified as 'protected' in that they can be protected by society whereby "individuals and states have an obligation to provide conditions under which people can - now and in the future - satisfy their objective needs, and/or conditions that do not make it impossible to satisfy these needs" (Di Giulio et al., 2012).

The role of public parks in relation to social inclusion and biodiversity is limited in Asia, as shown by research in Hangzhou, China (Wei, 2017), Taiwan (Wu and Song, 2017) and India (Baviskar, 2003). A comparative study between parks in the United States and 
China makes the case that green spaces are an environmental justice issue (Wolch et al. 20I4), further underscoring the necessity of linking public spaces, needs, satisfiers and societal wellbeing. Research suggests that access to green public spaces can provide health benefits, and therefore lack of access, often experienced by low income groups, is also a societal justice issue (Lee et al 20I I; Mitchell et al. 2008; Maas et al., 2006). There is robust literature on how green public spaces can exclude poorer communities, or lead to green gentrification (Gould and Lewis, 2017; Wolch et al., 2014; Arabindoo, $20 \mathrm{II}$ ), excluding the presence of poor, working class and people of colour, either directly or by increasing the price of real estate in surrounding areas. Implicated in this are different notions on what practices are deemed appropriate for green public spaces. Overall, there is a dearth of empirical research on what types of practices occur in green spaces, by whom and how these are linked to the satisfying of needs - underlining the importance to better understand the practices of green public space 'users'. Limited empirical research exists on how people interact with public spaces in emerging economies, including the material arrangements of these spaces, people's dispositions and ways of using these spaces, and the social norms governing these practices. This is why, in our research, we adopt a social practice approach. Practice-based approaches decentre individual attitudes and values as determinants of consumption behaviour, and instead place social practices at the centre of analyses. In one definition, social practices are routinized activities made up of material arrangements of spaces, people's dispositions and social norms, executed by skilled practitioners (Sahakian and Wilhite, 2014). Practices are the means by which people satisfy their needs, while also signalling social distinction and belonging (Anantharaman, 20I7; Carfagna et al., 20I4), two vital ways of establishing community. Thus, the practice lens offers a valuable way by which we can understand how people satisfy needs in and through green public spaces. The spatialized nature of satisfying needs through the performance of social practices is understudied, and could serve as a way of linking consumption studies to questions around the use of urban space.

\section{Methodology}

In order to understand in what way green, public spaces contribute to 'sustainable wellbeing', the research design involved understanding: I) How do people practice green public spaces in daily life; and 2) Towards what needs and for whom do green public spaces act as satisfiers? The qualitative research in parks in the cities under study involved a two-pronged approach: first, we asked people a series of questions related to their park practices; then, we invited participants to reflect and react to the list of Protected Needs (Di Giulio and Defila, 2020, see Annex I; used in English, and translated into Chinese and Tamil by team members). For park practices, we designed the interview guide around elements of social practices, involving I) people's competencies and dispositions (e.g. what they like or dislike, how they feel about being in different areas, their most or least favourite spots, where they feel safe or unsafe, what they believe is meaningful to their lives), 2) material arrangements of these spaces (e.g. lighting, infrastructure and other facilities, landscaping), as well as 3) social norms and regulations (e.g. explicit rules or implicit guidelines about what people can or cannot do in the space, who can use or not use the space and in what occurrence). For this paper, we focus on material arrangements in relation to the activities associated 
with the 'going to the park' practice. For need satisfaction, the research teams printed a list of Protected Needs and presented it to the interviewees or read it to them, to discuss which needs are generally more or less relevant to them. We then asked whether the activities they carry out in the park allow them to satisfy one or several of these needs. We also discussed how the park relates to other spaces in the city and what is unique about the park.

We began with a pre-selection of green public spaces in the four cities, including parks and beach-fronts, then agreed on criteria for the selection of at least two parks per city based on a consideration for the diversity of park users, the accessibility of the park in relation to the city and transport options, and the significance of the parks in relation to cultural heritage, biodiversity or other features. The involvement of diverse stakeholders in the park management was also considered, as was the research team's access to the park and prior experience working in that space. We excluded parks that are natural reserves, are only visited infrequently, or solely designed for tourism, or for a fee, privileging parks where people have an attachment to that space for leisure, social gatherings and, in some cases, income generation. We also aimed for diversity in park users, in terms of age, gender, employment, and particularly social class. Ten to fifteen interviews took place in each park'.

\section{Results}

This section begins with an introduction to each research site, providing background information on their climate conditions and the role of green public spaces in urban development, and then an analysis of how and in what way the green public spaces meet Protected Needs in these contexts.

\section{INTRODUCING THE RESEARCH SITES AND CONTEXTUALIZING GREEN PUBLIC SPACES}

Table I: Overview of four research sites; population, climate

\begin{tabular}{|c|c|c|c|c|}
\hline & Chennai & Metro Manila & Shanghai & Singapore \\
\hline Population & 8 million & 12.9 million & 24. 18 million & 5.7 million \\
\hline Climate & $\begin{array}{c}\text { Tropical savanna } \\
\text { climate }\end{array}$ & $\begin{array}{l}\text { Tropical marine } \\
\text { climate }\end{array}$ & $\begin{array}{l}\text { Temperate, } \\
\text { subtropical }\end{array}$ & Tropical rainforest \\
\hline $\begin{array}{l}\text { Mean annual } \\
\text { temperature }\end{array}$ & $28.6^{\circ} \mathrm{C}$ & $30.8^{\circ} \mathrm{C}$ & $17.7^{\circ} \mathrm{C}$ & $27.5^{\circ} \mathrm{C}$ \\
\hline Area coverage & 426 sq. km & $619.6 \mathrm{sq} . \mathrm{km}$ & 6340.5 sq. km & $722.5 \mathrm{sq} . \mathrm{km}$ \\
\hline Population density & 25,000 persons/sq. km & 20,785 persons/sq. $\mathrm{km}$ & 2,059 persons/sq. km & 8,200 persons/sq. km \\
\hline $\begin{array}{c}\text { Park numbers } \\
\text { and land } \\
\text { coverage }\end{array}$ & $\begin{array}{l}525 \text { parks } \\
\text { Green cover: I5\% }\end{array}$ & $\begin{array}{c}480 \text { parks } \\
\text { Green cover: } \\
31 \%\end{array}$ & $\begin{array}{c}243 \text { parks } \\
\text { Green cover; } 20.8 \%\end{array}$ & $\begin{array}{c}423 \text { parks } \\
\text { Green cover: } \\
47 \%\end{array}$ \\
\hline
\end{tabular}

\footnotetext{
' At the time of this writing, analysis of the data is underway; we present a preliminary analysis of a subset of the total interviews in the parks, along with observations.
} 


\section{a. Green public spaces in Chennai}

Located on the south-east coast of India, Chennai (previously known as Madras) is India's sixth largest metropolis, and experienced significant growth and expansion since the liberalization of the Indian economy in the late 1980s. The hot season is from March to November, peaking in April-May at around 40 degrees Celsius. The monsoon season, from October to December, brings much needed rain to the city, which has recently experienced repeated cycles of drought and floods. In 2016, Chennai was hit by a cyclone that brought down a great number of trees across the city; many parks have not fully recovered their green cover (Ayappan et al, 20I2). Land is at a premium and land-use planning a site of frequent contestation and injustice. In spite of so-called city master plans that have sought to structure the city's expansion, growth has largely been unplanned. Infrastructure and amenities, including green spaces, are unevenly distributed. In some cases, the removal of informal settlements along waterways has been carried out to purportedly create eco-parks, revealing how park creation has been used as a tool to justify displacement of the urban poor (Raman and Coehlo, 20I2). Parks are owned by the Greater Chennai Corporation (GCC), and while there is a great diversity in the quality and size of the parks based on their location, there is little publicly-available information on the biodiversity and ecosystem services parks provide (a systematic review of the biodiversity importance of parks in Bangalore, India, provides some insight into the ecological importance of neighbourhood parks in Southern India, see Swamy et al, 2019). While the state manages most of these parks, certain parks in elite and middle-class neighbourhoods are managed by private companies as part of Corporate Social Responsibility programs. In some parks, civil society stakeholders, who tend to be middle class/elite, have taken an active interest in the local park and influenced decisions around management and access, sometimes to the detriment of other social groups.

\section{b. Green public spaces in Metro Manila}

Located on the northernmost island of Luzon, Metro Manila has a dry season lasting from November to April and a wet season from May to October. Having a wet and tropical climate provides more than adequate sunlight and rainfall to support green spaces within the city. The metropolis is comprised of seventeen local government units, one each for its sixteen highly urbanized cities and one municipality. Each local government unit is autonomous in planning and developing public spaces within their respective territories, with the National Parks Development Committee (NPDC) administering the development and maintenance of two major national parks in the capital city of Manila, the Rizal Park and the Paco Park. However, the private sector plays a significant role in shaping the outdoor spaces. Developers often engage in long term agreements with various cities across Metro Manila to convert large outdoor spaces and lands into malls, condominiums, office buildings, and residences. Among others, this results in the proliferation of privately-owned public open spaces whose existence are limited by the next building construction planned on its site. Increasing concrete coverage and loss of porous land have been identified among the leading factors leading to worsening floods in the city (Lagmay, 2017), contributing to the formation of an urban heat island: higher temperatures - as much as $2.96^{\circ} \mathrm{C}$ higher - in cities as compared to nearby rural areas (Tiangco, et al., 2008). Some non-profit private foundations (e.g., Winner Foundation, ABS-CBN Foundation) also manage parks in 
cooperation with government agencies. Demolition and rebuilding of inner cities, the norm in Metro Manila's State- and capitalist-led urban revitalization, often result in the displacement of groups without land tenurial security, and the loss of cultural heritage structures (Saloma and Akpedonu, 2019). With ever more crowded streetscapes and perceived or real rising crime rates, heavily guarded and surveilled spaces such as condominiums and malls offer those who can afford them a safe refuge from the traffic, noise and pollution. In such spaces, maintenance of public areas is usually assured, unlike other sites where public space is commonly neglected, overrun by informal settlers, or simply does not exist (Saloma and Akpedonu, 2016).

\section{c. Green public spaces in Shanghai}

Shanghai is located on the eastern edge of the Yangtze River Delta, with the East China Sea to the east, the Hangzhou Bay to the south. With a subtropical maritime monsoon climate, the city boasts relatively cold winters (average low of $\mathrm{I}^{\circ} \mathrm{C}$ in January), and hot, muggy and rainy summers with an average high of $32^{\circ} \mathrm{C}$; typhoons and rainstorms are common from late August till early September. Since China's economic reform in the late 1970s, Shanghai has experienced rapid expansion and urbanization, as it works to become one of the world's financial, trade and shipping hubs. This has triggered a series of ecological problems related to air and water quality (Shuqing Zhao et al, 2006), and has now stimulated demands from city-dwellers for better living environments and for more outdoor recreational areas. The Shanghai municipal government owns all 243 Parks in the city, with some key parks managed at the municipal level, while others managed by district authorities. The Shanghai Landscaping \& City Appearance Administrative Bureau and Shanghai Forest Bureau issues park ratings on a scale of I-5 stars; most parks have zero stars, some are rated between two to four stars; with very few parks (such as Shanghai Botanic Garden and Shanghai Guyi Park) receiving five stars. Park ownership and access regimes have changed in the past seventy years; prior to 1949 the city had few parks and some were private. The city took over all parks in 1949 but charged entrance fees till 2002, after which point most parks offered free entrance. Since 20l I, parks have been gradually extended their open hours in summer, with some parks, including Zhongshan Park, now open 24-hrs a day.

\section{d. Green public spaces in Singapore}

Singapore is a tropical, island city-state located in Southeast Asia, with a rich cultural diversity reflected in the four official languages of Mandarin Chinese, English, Malay and Tamil. Located on the equator, Singapore experiences high temperature levels and additional heat from the urban heat island effect. Ranked $9^{\text {th }}$ on the Human Development Index, Singapore is currently experiencing an aging population: the proportion of residents aged 65 years and over has increased from $8.7 \%$ in 2008 to $13.7 \%$ in 2018 , with fewer working-age proportionally. An area of over $720 \mathrm{sq}$. km. has been reclaimed through intensive land use planning, leading to considerable stress on the natural environment, especially in terms of the extensive import of sand. The government goes to great efforts to address issues related to local and trans-boundary pollution, promoting electric vehicles and renewable energies, for example. Ambitious efforts are also underway to create 'a city in a garden'. The National Parks Board presently administers over 423 parks in Singapore, with a vision of "transforming Singapore into a biophilic City in a Garden and to create the best living environment 
through greenery and recreation" (National Parks Board, 2019). A notable example is the Gardens by the Bay, a IOI-hectare park with greenery and flora, brought from other climate conditions and supported through micro-climatic glass house technologies. The Park Connector Network is a major step taken towards linking residential and commercial areas of the city to a park, garden or another natural site. The National Environment Agency (NEA) also plays an important role in keeping the green public spaces, with various rules existing to avoid littering for example. Moreover, rooftop greenery and vertical farming has flourished in the recent past, albeit not always publicly accessible. Earlier studies highlighted that Singaporeans mainly used public parks for exercise and recreation (Yuen, 1999); and that lack of access to parks, often experienced by lower income groups, can lead to societal justice issue (Lee et al., 20 I I).

\section{GREEN PUBLIC SPACES AS SATISFIERS TOWARDS MEETING PROTECTED NEEDS}

In this section, we provide first and exemplary insights on how parks meet Protected Needs (Di Giulio and Defila, 2020), for a diversity of people and in relation to material arrangements in the parks selected for this study. For this paper, only a subset of the data was treated, as analysis is ongoing. We focus particularly on Protected Needs (PN) 3, 4 and 7, and how material arrangements satisfy needs. We also consider how the parks relate to other spaces in the cities.

\section{a. Results in Chennai}

Chennai is a diverse city with significant neighbourhood-level variation across lines of class, language, caste and religion. To adequately capture this diversity in our sample, three parks were selected for study: Anna Tower Nagar Park located in an upper middle-class, planned neighbourhood, Nageshwara Rao Park, sited in the old-city centre surrounded by both residential and commercial establishments, and Perambur Park, a lower-income neighbourhood that was an erstwhile industrial suburb with a largely working class population While these parks are utilized by a diverse set of people, in terms of gender, age, and socio-economic background, temporal rhythms were observed in who used the park, when. In the early morning, parks are primarily the domain of middle-aged, middle class and elite individuals walking for exercise (generally more men than women). By mid-afternoon, the demographic shifts, with more women entering the parks for exercise, as well as a greater number of people coming to the parks for relaxation. In the afternoon, parks serve as a space for day labourers to nap and get some respite from the heat, as well as a place for students to gather. In the early evening, couples dot the landscape, parents watch children play, and exercise walkers return. Late evening sees the parks become more of a social space, with vendors selling food at the gates or inside the parks.

In a material reading of park practices, these diverse uses were enabled by park amenities. Park visitors who come for exercise utilized paved walkways and outdoor gym equipment. The parks were also equipped with benches for people to sit and gather, and lawns for larger groups to sit. All the parks also had play equipment for children and toilets for general use. Two parks had filtered water dispensers. Beyond these built amenities, park users benefited from shade provided by trees. However, not all parks offer the same services: Anna Nagar Tower Park and Nageshwara Rao Park had significantly more tree cover and shade than Perambur Park, which is located in a lower-income neighbourhood. Similarly, the play equipment and walkways in the parks 
were in different states of repair and disrepair, pointing again to the significant differences in park quality and size. Use was also regulated by explicit and implicit norms. The parks studied were open between 5am and 6am, depending on the time of the year, and closed by around 10pm. Both Permabur and Nageshwara Rao Park were also closed during the day from I lam to 3pm, ostensibly to deter sleeping in the park. The parks studied do not allow vending within the premises, though some mobile vendors were observed serving park users local and home-made snacks. While we could not find explicit rules listed in all the parks, several park users indicated that it is against the rules to sleep in the park, bring pets inside, drink or smoke, or litter.

In terms of need satisfaction, only one out of the nine Protected Needs was not related to activities in the park by respondents (PN 8, to have a say in the shaping of society); in two parks, Nageshwara Rao and Perambur, PN9 (to be protected by society) was also not related to park activities. With a view to PN 3 (to live in a liveable environment), respondents cited the importance of trees in providing shade and something pleasant to look at, and contrasting the 'fresh and clean' air of the park to the busy and noisy street environments right outside. The natural landscape of the park was seen as unique; attracting users from beyond the immediate neighbourhood. Activities that were emphasized in this context were walking in the park, sitting in the park, and enjoying the environment. Satisfying PN 4 (to develop as a person) was linked with activities such as meeting friends, talking freely and openly, and relaxing in a space that is less controlled as other spaces such as home. In terms of PN 7 (to be part of a community), some come in groups, some come alone, but all enjoy the feeling of being with other park users - being connected to others, whether to gather with friends or simply experience being around others and practicing the park in similar ways.

The layout of all three parks permitted a diversity of activities by a diversity of people, occurring at the same time. The central areas of the park had play-areas for children, surrounded by benches, perched on which caregivers could watch children play and socialize with each other. The parks also had areas for group-games such as football and cricket, used primarily by groups of young men. Paved walkways covered the outerperimeter of the parks with additional pathways crisscrossing the centre, offering the mostly middle-aged and elderly walkers several options for walking. In Anna Nagar Park, one pathway circled an artificial pond, leading to a partially secluded area with benches. Here, several young couples were observed, availing of the privacy to engage in casual acts of intimacy. The layout of all three parks enabled communal activities of different types; Nageshwara Rao park had two stage areas where youth groups could be seen practicing for a dance show, and all parks had several smaller group gathering areas. Beyond this, several parts of the parks are laid to lawn, and we spotted groups gathering to celebrate birthdays, and hold discussions that appeared more serious. However, older park users complained, however, about the lack of clustered-seating, meaning they did not have a good place to gather and talk.

Importantly, Anna Nagar park has a large and well-maintained public toilet block as well as drinking water. Access to water and toilets means users are able to spend extended periods at the park. These amenities were less available and well-maintained in the other two parks, where respondents complained that the toilets were dirty and drinking water unavailable. These attributes of the space, enabling extended hours of stay, were especially important to our working class and lower middle-class interviewees who lived in small homes and high-density neighbourhoods, where they did 
not have easy access to privacy or spaces to play, and who did not feel comfortable or 'free' in the glitzy, air-conditioned malls designed for elite consumption. In relation to other spaces in the city, the green public spaces allow people to talk freely and feel comfortable, and less controlling as other spaces such as shopping malls, neighbourhood streets and, for some people, especially women, their homes.

\section{b. Results in Metro Manila}

Two parks were included in the study, Rizal Park and the University of the Philippines (UP) Academic Oval, and for both, the socio-economic profiles of park users were mainly lower- and middle-income group. Rizal Park, set in an urban area, does not have entrance gates (even though roving guards are constantly present) and thus welcomes a mix of the homeless people and jobseekers, who pass the day at the park, as well as people who access the park to earn a living - such as itinerant vendors and photographers. In contrast, users of the UP Academic Oval tend to be homogenous (i.e., alumni, faculty, students, and staff and their families and friends) since UP, though served by a public transportation route, is not accessible on foot from the nearest public space and, except, for the main entrance, require vehicle pass stickers. Both lowand middle-class groups tend to use the parks for exercise, relaxation, and family bonding. Students who are rehearsing group performances, engaging in sports, or simply hanging around are likewise a constant fixture in parks: Rizal Park due to its proximity to colleges and universities; the UP Academic Oval because it is located within the University of the Philippines campus.

In terms of material arrangements, parks, as open public spaces, have very few roofed structures, which means rains and floods, on the one hand, and hot, humid weather on the other, limit park usage. Access to clean public toilets is also another concern, with park users usually planning their stay so as not to have to use the toilet, or planning to end with a visit to a nearby fast food restaurant. Rizal Park, despite its urban setting, is home to a wide variety of wildlife, including a range of birds and over 3,424 trees (Gonzales and Magnaye, 2017); of particular significance is the Rizal monument, a memorial to the $19^{\text {th }}$ century nationalist, José Rizal. Together with grassy lawns and shaded picnic areas, the trees in both parks provide some respite from the city's heat and noise. Park goers cite the cooler temperatures, the breeze, the abundant greenery, and quiet atmosphere as part of the reasons why they visit and spend time in the area. In terms of need satisfaction, only one of the nine Protected Needs was not related to activities in the park by the respondents (PN 2). For many park visitors, the park fulfils, first and foremost, their need for self-development (PN 4, to develop as a person), and activities satisfying this need include not only having a quiet time on one's own for thinking and reflection, but also running to rejuvenate the mental state. Some of these activities are, at the same time, activities satisfying PN 6 (to perform activities valuable to them), such as physical activities, or thinking and reflection. Furthermore, those who go to the park primarily to exercise usually do so on their own and do not see a need to be part of a collective, although they admit deriving inspiration and motivation from seeing others do what they themselves are doing (e.g., running, jogging). In contrast, PN 7 (the need to belong to a group or a community) is the primary need being met for those who visit the park to bond with family and friends. For park vendors and photographers, it is the need for life's basic necessities, or livelihood opportunities (PN I), and for the homeless, the need for a liveable environment (PN 3) and to be 
protected by society (PN 9). Having stayed in the park for quite a long time, they have formed social relationships among each other. We could observe no gender differences in park space usage, with both men and women feeling safe and free to pursue in the park whatever it is that does not breech any social norm, such as the public display of affection.

Park users, in general, recognize the right of others to the park. Low-income groups feel a sense of equality and appreciate it that one can stay in the park without having to spend for anything. While some park users complain of high prices of items sold by small-scale vendors, others, mostly occasional buyers, are happy to patronize them. The middle-income groups likewise do not feel threatened by the presence of homeless people who stay in the park the whole day, until it closes at night. The latter are usually neatly dressed and stay together in specific areas. Park users also tolerate groups who use the park to evangelize or to talk politics.

However, whereas the sense of security and being protected in parks is mostly attributed to the presence of security guards, the same presence can make others such as the homeless and vendors - feel a sense of precarity. Another area, however, where park users differ is in the collection of fees: in comparison with lower-income park users, most middle- and upper-income users seem to prefer mutual coercion, such as the collection of fees toward a better management of the park commons. Thus, they would not mind paying for the use of clean toilets. Territoriality issues likewise arise when, over time, certain spaces become associated with a particular group. 'Old' and 'new' groups often find simultaneously asserting and contesting each other's right to space.

A few park goers claim that they prefer to spend time in the parks because there is much more to see and do as compared to an air-conditioned shopping mall, which have more access- and behaviour-controls. For people who deliberately go to the park to find a quiet space for reflection, the physical attributes of the park such as shady trees and cool breeze help them to be calm and feel more in tune with nature. With firsttime travellers to Metro Manila from the provinces invariably including a visit to Rizal Park as a patriotic act, and with UP Academic Oval users pointing to the uniqueness of its arbour and sunken garden, parks are a site for natural and cultural heritage enjoyment when they harbour native plants and translocated heritage structures or built memorials, which are important aspects of national identity.

\section{c. Results in Shanghai}

In Shanghai, observations and interviews were conducted in two parks, Zhongshan Park and Daning Park. Built in 19/4 and located in Changning District, Zhongshan Park (originally Jessfield Park) occupies 2I4,200 square meters (53 acres), and is a fourstar rated park, with more than 30,000 trees of 260 species. A famous park in downtown Shanghai, the park combines English-style landscapes with the architectural style of classic Chinese gardens. Some of its well-known scenic spots are the Great Lawn, the Chinese Rose Garden, the Lake of Mandarin Ducks, the Lotus Pond, the Hill and Water Garden, the White Marble Pavilion. In contrast, the three-star Daning Park (also called Daning Lingshi Park or Daning Tulip Park) in Jing'an District is newer and was opened to the public in 2002. This is officially the largest centralized green in Puxi (west of Huangpu River), with 310,000 trees, 216,000 square meters, grass and other ground cover plants, and more than 200 species of plants. It has a man-made beach and 
lake where people play, fish, and take wedding pictures, and ample green space for flying kites, exercise or jogging. The north part consists of hills, woodland, the big lake and beach. The southern stretch is an assortment of ponds, streams, swamps, and kitsch viewpoints. The east side of the park is the site of its predecessor, Guanzhong Park, and hosts a restaurant, several statues representing Chinese traditional legends and fairy tales, a few token bamboo paths. The middle of the park also has a garden, including tulip fields and fake Holland-style windmills, and several Roman-style features including a square where events take place. Daning Park hosts Shanghai's biggest tulip exposition or tulip festival, with what they say are millions of different tulips on display. Though the park is replete with artificial landscapes, the north entrance sign posted by the Shanghai Landscape Administration Bureau reads: "The ethereal, peaceful, picturesque nature landscape of Daning-Lingshi Park has become the favourite for urbanites, therefore it ranked top ten Greatest Sights in Shanghai during a 2005 activity held by Youth Daily, and is also recognized as one of 'Shanghai Civilized Parks.'"

Most people appreciate the current situation in the parks, including landscape, design, environment, facilities, infrastructures and the people they interact with. Generally speaking, park users appreciate the natural setting, such as the gardens, open spaces, lawn areas, and ponds or lakes, as well as park amenities such as pavilions, chairs or benches, and playgrounds, using these for exercise, rest, relaxation and meeting friends. Though toilet smell and hygiene conditions make international visitors uncomfortable, Chinese users get used to them. They feel safe and protected, moving about the park easily and freely, though regular visitors know to avoid a specific tree-covered hill area where several middle-age sex workers accost male passers-by. They speak freely or hear others speak quite freely about current affairs, barring religious and political issues, which they do keep as private conversation. There are no group or collective activities on these topics either. Regarding the park resources and management, they seldom complain; few criticize the management of parks, assuming their voice means little or nothing at all while the government and the administration will decide everything. In terms of need satisfaction, all nine Protected Needs were related to activities in the parks by respondents. In relation to the park, PN 3 (to live in a liveable environment) was much more important than PN 4 (to develop as a person) and PN 7 (to be part of a community). Respondents mentioned a broad diversity of activities that they linked with satisfying PN 3, such as for example enjoying the environment, relaxing, doing exercise, doing nothing in particular, fishing, walking in the park, or sitting in the park - and some of these activities, such as walking, relaxing, and doing exercise, serve PN 4 as well. Regular users come to the park to joining in group activities such as dancing, boxing, Taiji, singing, a music band, playing chess or majiang, among others. Given the fact Shanghai is becoming a city with an aging population and little public space for the residents, elderly people use public parks as the first choice of their outdoor activities. For them, parks are also a place where they chat, see familiar people or strangers, maintain established social connections or maybe start new ones (PN 7).

Within the parks, there is no obvious social exclusion since parks are open to everyone, but it seems not easy to join in established regular group users such as the band, dancing team, opera group, among other activities. People appreciate what the park offers in contrast to the noisy and busy atmosphere outside the park, where within walking distance fast-paced shopping malls and air-conditioned spaces in the city often make them feel dull, stressful, oppressive or depressed. Parks are unique spaces in the 
city - particularly for elderly people, but also for those who enjoy nature and group activities, such as dancing.

\section{d. Results in Singapore}

Research was conducted in two Singapore parks, namely Botanical Gardens and East Coast Park (ECP). While the botanical gardens are a vast, 82-hectare area, located in the heart of the city, the ECP has a total land size of 185 hectares, and a scenic coastline that stretches over $15 \mathrm{~km}$, facing the east. The research team covered fifteen responses from each park and received interesting responses from a wide range of population in terms of the demographic profile of the respondents. The comfortable standard of living in Singapore has attracted a burgeoning expatriate community, constituting foreign workers and their families, not only from nearby Asian countries but also from the rest of the developed world. Despite the majority of respondents being Singaporean, other respondents hailed from nations such as Malaysia, Indonesia, India, the Philippines,

China, Taiwan, Germany and Spain. Some of the primary purposes of park usage included walking, exercising, resting, meeting friends and having a picnic with family members.

In terms of material arrangements, the respondents cited the presence of water bodies as a highly appealing natural setting, both at ECP and Botanical Gardens. It is vital to make a distinction here, as the former is a coastal landscape with a beach and a jetty, popular for activities such as fishing and kayaking. The latter, on the other hand, is more of an educational establishment with exhibits displaying engaging information about the flora and fauna of Singapore; the water body here is a lake with birds and animals such as turtles and swans. A relative lack of noise and air pollution, as compared to the city centre, was cited as another reason for visiting the two parks. Rules have to be followed while visiting these parks and visitors are more or less aware of the rules, like for example - swimming is not allowed in the sea along the ECP, while feeding animals and camping are not allowed in Botanical Gardens among other rules mentioned. In terms of need satisfaction and similarly to Chennai, only one out of the nine Protected Needs was not related to activities in the park by respondents (PN 8, to have a say in the shaping of society). PN 3, 'to live in a liveable environment', PN 5, 'to make their own life choices' and PN 9, 'to be granted protection by society' were most frequently selected as important and relevant needs by respondents in both parks. Most respondents linked the satisfaction of PN 3 to the activities that they perform at the park which include walking, doing exercise, relaxing, enjoying the natural heritage, or sitting in the park. The respondents also added that the coastal green landscape of ECP added to their wellbeing, whereas in Botanical Gardens, flora and fauna and the soothing water body with turtles and swans led to self-satisfaction. PN 4, 'to develop as a person', was linked with activities such as meeting friends or family, reading in the park (e.g., news, books), discovering oneself through meditation and contemplation, praying in the park or writing a journal in the park, and some activities, such as relaxing, enjoying the natural heritage (e.g., trees) or doing exercise served both, PN 3 and PN 4. At both parks, the most common activity was 'doing nothing in particular, like to sit or walk around the park', closely followed by 'like to rest and relax in the park, or sleep in the park'. Respondents linked many activities to PN 7, 'to be part of a community', and these covered not only meeting friends or family (e.g., for picnics, fishing, eating together, birthday celebrations etc.), and joining in group exercise, but also enjoying the 
natural heritage, and sightseeing, or attending religious celebrations in the park (e.g. Holi).

According to our respondents, the lush greenery and soaring palm trees of ECP, the array of flora and fauna, the pristine environment of the Eco Lake and fresh air remains unparalleled in comparison to the concrete air-conditioned shopping malls, as these malls in no way feel as natural as these open breezy spaces. The parks seem to be unique spaces for relaxing and doing physical activities, and the natural features seem important to Singaporean identity.

\section{Discussion and conclusion}

In this study, we set out to understand how parks satisfy human needs by uncovering needs in practice, and in relation to material arrangements. What we have found across all of the research sites is the importance of green public spaces in satisfying a variety of the needs covered by the list of Protected Needs that we used, such as living in a liveable environment (PN 3), developing as a person (PN 4) or being part of a community (PN 7), but also others of these needs (see table 2). In presenting results, we focused particularly on PN 3, PN 4, and PN 7. The results for these needs show, first, that although the cultural contexts differ, and although the practices that are enacted in the parks differ from city to city, the parks tend to meet similar needs across the research sites. Secondly, the results point out the importance of the cultural and natural heritage in most of the parks: this heritage satisfies different needs and is thus synergistic with a view to wellbeing. In relation to material arrangements, different features are important in parks, such as benches, activity areas for adults and children, walking lanes, but also lighting and basic services such as toilets, water fountains, shade from the sun, or shelter from the rain. In all cases and as discussed elsewhere, it is the park practices which enable need satisfaction (Sahakian and Anantharaman, 2020, in press), made possible through certain material arrangements. A third point relates to the significance of recreative and non-commercial practices, such as walking in the park, sitting in the park, or doing nothing in particular, and in opposition to other spaces such as shopping malls. Finally, these results uncover that parks provide not only a space in which people can gather with friends and family for joint activities, but also a space in which people can experience the feeling of being with others, or of belonging to a community.

At the same time, green public spaces are a limited resource, both in relation to space allocation and types of usages. This leads to two main points of tension, in relation to competition between users, and in relation to competition for space, as we will now detail. Green public spaces as satisfiers for needs by one segment of society can compete with need satisfaction by other segments of the same society. In Singapore, potential conflict of interest prevails among social groups at East Coast Park: the older Singaporeans seem to be dissatisfied vis-à-vis the usage of the barbeque pits by Malaysian teenagers, on the grounds of excessive noise and littering, during a period when they seek peace and relaxation in a natural setting. For avoiding such conflicts, the government has set up a booking system to allow residents to reserve common public infrastructure for private use temporarily, and free of charge. In Chennai, conflicts between park users are mostly in relation to class: elite and middle-classes frequent parks for exercise, often at the exclusion of other park stakeholders such as 
vendors who might sell goods outside the park or poor people who might want to use parks for other purposes. In Shanghai, parks during certain periods of the year can be simply over-run by people: having a space for respite from the busy city may necessitate more green public spaces, in order to satisfy the needs of residents as well as a growing migrant population.

Table 2. The Protected Needs that are satisfied in the parks.

Dark table cells $=$ respondents say that the Protected Need is satisfied by practices in this park.

Number in the table cell = number of interviews in which the Protected Need is explicitly mentioned.

\begin{tabular}{|c|c|c|c|c|c|c|c|c|c|}
\hline \multirow[t]{2}{*}{ City/park } & \multicolumn{9}{|c|}{ Protected Needs I-9 } \\
\hline & $P N I$ & $P N 2$ & PN 3 & PN 4 & PN 5 & PN 6 & PN 7 & PN 8 & PN 9 \\
\hline \multicolumn{10}{|l|}{ Chennai } \\
\hline Anna Nagar Park & & 3 & 9 & I & & 8 & 8 & & 2 \\
\hline $\begin{array}{r}\text { Nageshwara Rao } \\
\text { Park }\end{array}$ & T & 4 & 7 & 4 & I & 4 & 4 & & \\
\hline Perambur Park & 3 & 3 & 6 & I & & & 2 & & \\
\hline \multicolumn{10}{|l|}{ Metro Manila } \\
\hline Rizal Park & $\mathrm{I}$ & & & 3 & & 2 & 10 & $\mathrm{I}$ & $\mathrm{I}$ \\
\hline $\begin{array}{r}\text { UP Academic Oval } \\
\text { Park }\end{array}$ & 2 & & 6 & 4 & $\mathrm{~T}$ & 4 & 6 & & 2 \\
\hline \multicolumn{10}{|l|}{ Shanghai } \\
\hline Danning Park & 9 & 4 & II & I & & 6 & & I & 2 \\
\hline Zhingshan Park & 3 & 5 & 10 & 2 & 3 & 9 & 6 & & $\mathrm{I}$ \\
\hline \multicolumn{10}{|l|}{ Singapore } \\
\hline $\begin{array}{r}\text { Botanical Garden } \\
\text { Park }\end{array}$ & 5 & 4 & II & 6 & 5 & 4 & 9 & & 2 \\
\hline East Coast Park & 4 & 9 & II & 6 & 6 & II & 10 & & 5 \\
\hline
\end{tabular}

Parks also compete for space in the city, with capitalist-led pressure to build more condominiums and malls on public space, as well as the propensity of local governments to erect multipurpose buildings on green spaces, as is the case in Metro Manila. In this context, the creation of green public spaces is expensive and a great opportunity cost in relation to deals that could instead be made with real estate developers; hence if the national and local governments are to invest public funds into the creation and/or maintenance of public space such as parks and plazas, they must be assured that these places will be patronized accordingly. 'Green, Green, Green', a program that funds the development of public open spaces in the country's I45 cities, and which accompanies the national infrastructure development program, 'Build, Build, Build', is therefore a welcome development, albeit not without the bureaucratic limitations usually plaguing government initiatives. In Chennai, plans to create new parks often involve the removal of informal settlements or slums where the poor and working class live. For example, a recent decision to create an Eco-Park on the banks of the Adyar river in Chennai resulted in the displacement of several hundred households that were living on the banks of the river. Parks in Chennai are also under threat, as they are farmed out to 
development projects to store material, such as for the Chennai Metro. In Shanghai, too much top-down planning, regarding the design, landscape, management, or rules and policies of parks, is leading to a homogenization of these green public spaces - which might also be a detractor for park users, and particularly elite groups. In Singapore, land leasing from Urban Redevelopment Authority (URA) has allowed for the implementation of a master plan towards greening the city, which seems to be effective in preventing encroachment; there seems to be no question of conflict of private space over public space arising for land. Although Singapore has placed an emphasis on its development as a green city and increased the land area dedicated to parks, the park provision ratio has consistently stayed below planning targets.

If green public spaces are to thrive in the cities of South and Southeast Asia, it is critical to underline how they provide need satisfaction for a diversity of people. Ultimately, green public spaces and their material arrangements offer distinct microclimates from other places in the city, including commercial centres. With air-conditioning usage contributing to both carbon emissions and urban heat island effects, it becomes critical to find ways to promote microclimate diversity - included passively cooled and shaded areas, which parks tend to offer. While they may promote healthier lifestyles and environmental biodiversity, as already demonstrated in the literature, they also meet a variety of other needs, as we have demonstrated in our study. What remains to be understood is how urban development projects can help maximize green public spaces as unique satisfiers for meeting the needs of a diverse group of people, while minimizing the use of resources for other spaces in the city that may not meet needs as synergistically - either because they focus on the needs of a privileged few, in gated communities for example, or provide forms of leisure that are energy-intensive and focus on desires rather than Protected Needs, such as shopping centres. We argue for placing Protected Needs at the centre of deliberations on the use of public spaces, while accounting for social- and micro-climate diversity.

\section{Acknowledgment}

This article draws from a research project funded by the Swiss Network for International Studies. We are grateful to the Institute of Sociological Research for supporting Prof. Manisha Anantharaman's stay at the University of Geneva as Alba Viotto Visiting Professorship. We would like to thank our research teams in each city, the special issue editors and reviewers, as well as all of the participants who agreed to be interviewed for our study.

\section{References}

Abercrombie, L. C., Sallis J. F., Conway, T. L., et al. (2008). Income and racial disparities in access to public parks and private recreation facilities. American Journal of Preventive Medicine 34: 9-15.

Alkire, S. (2010). Human Development: Definitions, Critiques, and Related Concepts. Background paper for the 2010 Human Development Report. Oxford Poverty \& Human Development Initiative (OPHI). Working paper 36. Oxford: University of Oxford.

Anantharaman, M. (2017). Elite and ethical: The defensive distinctions of middle-class bicycling in Bangalore, India. Journal of Consumer Culture, I 7(3), pp. 864-886. 
Ayyappan, K., Thiruvenkatasamy, K., \& Arumugam, T. (2017). Impact Assessment Study of Cyclone Vardah on Chennai, On East Coast of Tamil Nadu, India. TIDEE (TERI Information Digest on Energy \& Environment), I6(I).

Barbosa, O., Tratalos, J. A., Armsworth, P. R., et al. (2007). Who benefits from access to green space? A case study from Sheffield, UK. Landscape and Urban Planning, 83, pp. 187-195.

Boone, C. G., Buckley, GL, Grove, J. M., et al. (2009). Parks and people: An environmental justice inquiry in Baltimore, Maryland. Annals of the Association of American Geographers 99: 767-787.

Carfagna, L. B., Dubois, E. A., Fitzmaurice, C., et al. (20/4). An emerging eco-habitus: The reconfiguration of high cultural capital practices among ethical consumers. Journal of Consumer Culture, I4, Pp. I58-I78.

Costanza, R., Fisher, B., Ali, S., Beer, C., Bond, L., Boumans, R., Danigelis, N. L., Dickinson, J., Elliott, C., Farley, J., Elliott Gayer, D., MacDonald, G.L., Hudspeth, T., Mahoney, D., McCahil, L., McIntosh, B., Reed, B., Turab Rizvi, S. A., Rizzo, D.M., Simpatico, T., \& Snapp R. (2007). Quality of life: An approach integrating opportunities, human needs, and subjective wellbeing. Ecological Economics, 6I, pp. 267-276.

Cornelis, J. \& Hermy, M. (2004). Biodiversity relationships in urban and suburban parks in Flanders. Landscape and Urban Planning 69: 385-40I.

Cummins, R. (1996). The Domains of Life Satisfaction: An Attempt to Order Chaos. Social Indicators Research 38 (3): 303-328.

Department of Environment and Natural Resources - Biodiversity Management Bureau (DENRBMB) (2016). Ninoy Aquino Parks and Wildlife - History. Retrieved 22 April 2019, from http://www.bmb.gov.ph/napwc-history.

Department of Environment and Natural Resources (DENR). (2019). National Capital Region. Retrieved 20 April 2019, from https://ncr.denr.gov.ph/index.php/about-us/regional-profile.

Di Giulio, A., Brohmann, B., Clausen, J., Defila, R., Fuchs, D., Kaufmann-Hayoz, R., \& Koch, A. (2012) Needs and consumption - a conceptual system and its meaning in the context of sustainability. In: Defila, R., Di Giulio, A., Kaufmann-Hayoz, R. (eds.): The Nature of Sustainable Consumption and How to Achieve it. Results from the Focal Topic "From Knowledge to Action - New Paths towards Sustainable Consumption". München: oekom. S. 45-66.

Di Giulio, A., and Defila, R. (2020). The 'Good Life' and Protected Needs. In A. Kalfagianni, D. Fuchs, \& A. Hayden (Eds.), The Routledge Handbook of Global Sustainability Governance. London: Routledge.

Dolan P., Peasgood T. and White M. P. (2008). Do we really know what makes us happy? A review of the economic literature on the factors associated with subjective well-being. Journal of Economic Psychology, 29, Pp. 94-I22.

Doyal, L. \& Gough, I. (1991). A Theory of Human Need. Macmillan.

Gross, M. (2010). Ignorance and surprise: Science, society and ecological design, USA: The MIT Press.

Gonzales, L. P. \& Magnaye, D. C. (20I7). Measuring the urban biodiversity of green spaces in a highly urbanizing environment and its implications for human settlement resiliency planning: The case of Metro Manila, Philippines. Procedia Environmental Sciences. 37, pp. 83-I 00.

Gough, I. (2017). Heat, Greed and Human Need: Climate change, capitalism and sustainable wellbeing, UK, USA: Edward Elgar Publishing Limited.

Habermas, J. (1989). The Structural Transformation of the Public Sphere: An Inquiry into a Category of Bourgeois Society, Cambridge Massachusetts: The MIT Press.

Hitchings, R. \& Jun-Lee, S. (2008). Air conditioning and the material culture of routine human encasement: The Case of Young People in Contemporary Singapore. Journal of Material Culture 13: 25।-265.

Kowarik, I. (20II). Novel urban ecosystems, biodiversity, and conservation. Environmental Pollution, 159, Pp. 1974-1983. 
Krenichyn, K. (2006). The only place to go and be in the city: women talk about exercise, being outdoors, and the meanings of a large urban park. Health \& Place I2, PP. 63I-643.

Lagmay, A.M ., Mendoza, J, Cipriano, F, Delmendo, P. A., Lacsamana, M. N., Moises, M. A., Pellejera, N., Punay, K. N., Sabio, G., Santos, L., Serrano, J., Taniza, H. J., Tingin, J. E. (20I7). Street floods in Metro Manila and possible solutions. Journal of Environmental Sciences. 59:3947. https://doi.org/I0.1016/j.jes.2017.03.004.

Lee, A. C. K., and R. Maheswaran (20II). The Health Benefits of Urban Green Spaces: A Review of the Evidence. Journal of Public Health 33 (2), pp. 2I2-22, https://doi:10.1093/pubmed/fdq068.

Lefebvre, H. (1967) Le droit à la ville. L'Homme et la société 6, pp. 29-35.

Max-Neef M, Elizalde, A., Hopenhayn, M. (1989). Human Scale Development: an option for the future. Development Dialogue I, Pp. 17-47.

Max-Neef M.A., Elizalde A., and Hopenhayn M (199I). Development and Human Needs. In: Max-Neef M. A. (ed.): Human scale development: Conception, application and further reflections. London: Zed Books, pp. I3-54.

National Parks Board (2019). Biophilic City in a Garden. https://www.nparks.gov.sg/about-us/cityin-a-garden. Last Accessed 7 May 2019.

Nor, A. Constanje, R. Harris, J. Brewer, T. (2017). Impact of rapid urban expansion on green space structure, Ecological Indicators, Volume 8I, pp. 274-284.

Nussbaum, M. C. (1992). Human functioning and social justice: In defense of Aristotelian essentialism. Political Theory 20/2, pp. 202-246.

Philippine Statistics Authority. (2018). Quickstat on National Capital Region (https://psa.gov.ph/quickstat/national-capital-region).

Philippine Statistics Authority. (2018). Land asset accounts for tree-covered areas in the Philippines. Progress Report Series of 2018 no. 2. Metro Manila: Philippine Statistics Authority.

Retrieved from https://psa.gov.ph/sites/default/files/Land\%20Asset\%20Accounts\%20for\%20TreeCovered\%20Areas\%20of\%20the\%20Philippines.pdf; Last accessed: 20 April 2019.

Rao, N. D. and Min J. (20I7). Decent Living Standards: material prerequisites for human wellbeing. IIASA Working Paper. Laxenburg, Austria: IIASA.

Coelhi, K., \& Raman, N. V. (20I0). Salvaging and Scapegoating: Slum Evictions on Chennai's Waterways. Economic and Political Weekly, 45(21), 19-23. Retrieved from JSTOR.

Robeyns I. \& van der Veen R. J. (2007). Sustainable quality of life: Conceptual analysis for a policyrelevant empirical specification. Bilthoven, Amsterdam: Netherlands Environmental Assessment Agency and University of Amsterdam.

Ryan, R. M., \& Deci E. L. (2000). Self-Determination Theory and the Facilitation of Intrinsic Motivation, Social Development, and Well-Being. American Psychologist 55 (I), pp. 68-78.

Ryff, C. D. (1989). Happiness Is Everything, or Is It? Explorations on the Meaning of Psychological Well-Being. Journal of Personality and Social Psychology 57 (6), Pp. I069-I08I.

Roesler, S. \& Kobi, M. (2018). The Urban Microclimate as Artifact: Towards an Architectural Theory of Thermal Diversity. Birkhäuser, 200.

Sahakian, M. (20I4). Keeping Cool in Southeast Asia: Energy use and urban air-conditioning, New York, London, UK: Palgrave Macmillan.

Sahakian, M. \& Anantharaman, M. (2020, in press). What space for public parks in consumption corridors? Conceptual reflections on need satisfaction through social practices, Sustainability: Science, Practice and Policy.

Sahakian, M. \& Wilhite H. (20l4). Making practice theory practicable: towards more sustainable forms of consumption. Journal of Consumer Culture, 14, Pp. 25-44.

Saloma, C. \& Akpedonu E. (2016). Eating in vertical neighbourhoods: Food consumption in Metro Manila's condominiums in: Food consumption in the city: Practices and patterns in urban Asia and the Pacific. Marlyne Sahakian, Czarina Saloma, and Suren Erkman (eds.), Oxford: Routledge, Pp. 90-106. 
Saloma, C. \& Akpedonu, E. (2019). Bridging Manila's Chinatown and Intramuros: The Belt and Road Initiative and its Consequence for Historic Districts. Social Transformations: Journal of the Global South. 7(2), pp. 25-56.

Seeland, K., Duibendorfer, S. and Hansmann R. (2009). Making friends in Zurich's urban forests and parks: The role of public green space for social inclusion of youths from different cultures. Forest Policy and Economics, II, pp. I0-17.

Shanghai Bureau of Statistics (2016). Shanghai Statistical Yearbook (2016). Retrieved November 26th, 2016 from http://www.stats-sh.gov.cn/tjnj/nj I6.htm?d=2016tjnj/CI I I5.htm.

Shuqing, Z. et al (2006). Ecological consequences of rapid urban expansion: Shanghai, China, Frontiers in Ecology and the Environment, Vol. 4, No. 7, China's Environmental Challenges: The Way Forward (Sep. 2006), pp. 34I-346.

Swamy, S., Nagendra, H., Devy, S., (2019). Building biodiversity in neighbourhood parks in Bangalore city, India: Ordinary yet essential. PLOS ONE 14, e0215525. https://doi.org//0.137I/journal.pone.0215525.

Tiangco, M., Lagmay, A. M. F., and Argete, J. (2008). ASTER-based study of the night-time urban heat island effect in Metro Manila. International Journal of Remote Sensing. 29:10 (2799-28I8). DOI: $10.1080 / 01431160701408360$.

Urry, J. (1995). Consuming Places, London and New York: Taylor \& Francis.

Veenhoven, R. (2008). Sociological Theories of Subjective Well-being. In: Eid M., Larsen R. (eds.): The Science of Subjective Well-being: A tribute to Ed Diener. New York: Guilford Publications. 44-6I.

Wei Yang, Nyuk Hien Wong, Steve Kardinal Jusuf (2013). Thermal comfort in outdoor urban spaces in Singapore, Building and Environment, 59, pp. 426-435.

World Health Organization, (2010). Urban Planning, Environment and Health: From Evidence to Policy Action. (Retrieved October I0th, 2016 from http://www.euro. who.int/_data/assets/pdf_file/0004/I I 4448/E93987.pdf?ua=I).

Yuen, B., Kong, L., \& Briffett, C (1999). Nature and the Singapore resident. Geojournal 49(3): 323-33I.

Zhang Qing-fei et al (200I). Development Dynamic, Distribution Pattern and Scale Characters of the Park Systems in Shanghai, China Gardens/Zhongguo Yuanlin, 200I/I, Pp. 58-6I. 


\section{Annex I - Nine Protected Needs}

In order to reflect on need satisfaction in relation to green public spaces and for this study, we engaged with a list of nine Protected Needs, a novel approach to provide a thick theory of the good life for the purpose of developing sustainability policies. To operationalise the notion of a good life, nine needs are defined as protected in that they are needs which "(a) deserve special protection within and across societies because they are crucial to human well-being, and that are at the same time, (b) needs for which a special protection is possible, because they are needs for which a governmental/community responsibility can reasonably be assigned" (Di Giulio and Defila, 2020).

These needs denote what individuals must be allowed to want (universal needs) and the possibilities individuals should be provided with (thick descriptions of these universal needs). The descriptions of the needs are sensitive and dynamic with a view to cultural context and development in history. Di Giulio and Defila provide descriptions that are specified for the cultural context of Switzerland and Germany. These descriptions are meant to serve as a starting point to adapt the list of needs in terms of culture and time. The nine Protected Needs are arranged in three groups:

"Group I focuses upon tangibles, material things (Protected Needs I-3), group 2 focuses upon the person (Protected Needs 4-6), and group 3 focuses upon community

(Protected Needs 7-9):

(I) To be provided with the material necessities for life

(2) To realize their own conception of daily life

(3) To live in a livable environment

(4) To develop as a person

(5) To make their own life choices

(6) To perform activities valuable to them

(7) To be part of a community

(8) To have a say in the shaping of society

(9) To be granted protection by society" (Di Giulio and Defila, 2020). 


\section{The LiSt Of Protected NeEdS, IN THE FORMAT IN WHICH THEY WeRE USED FOR THE INTERVIEWS}

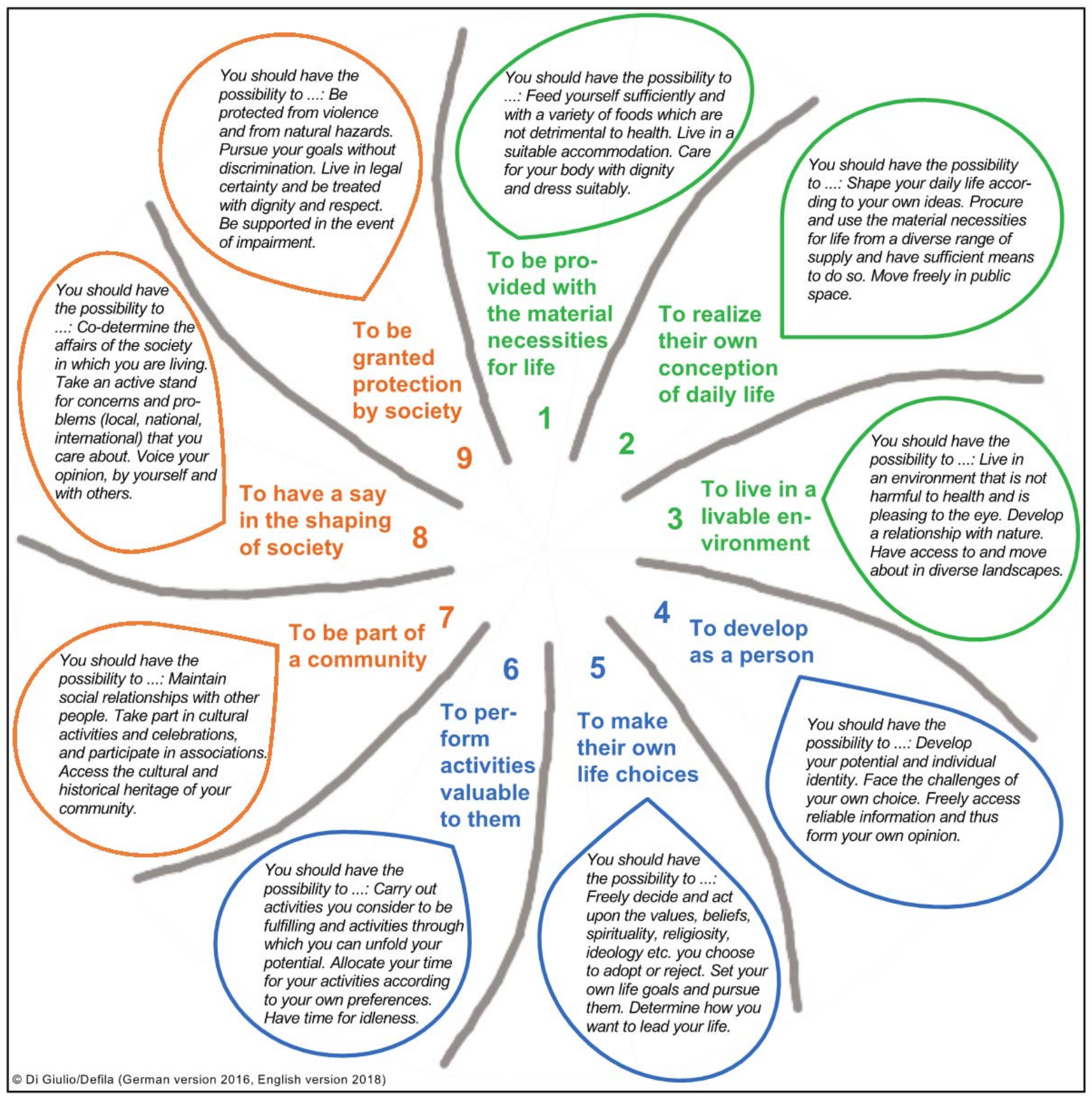

Figure I: building on Di Giulio, A., \& Defila, R. (2019). The 'Good Life' and Protected Needs.

In F. D. Kalfagianni A., Hayden A. (Ed.), The Routledge Handbook of Global Sustainability Governance.

London: Routledge. For the interviews, the thick descriptions of the Protected Needs provided by

Di Giulio and Defila were summarized. These summaries have been collaboratively developed by Antonietta Di Giulio, Manisha Anantharaman, Marlyne Sahakian, and Czarina Saloma, based on discussions with the entire research team. 